\title{
Tobacco Smoking in Patients of Therapeutic Hospital in Izhevsk, Russia
}

\author{
Sergei Pakriev* \\ Department of Psychiatry, Russia \\ *Corresponding author: Sergei Pakriev, Department of Psychiatry, Russia
}

\section{ARTICLE INFO}

Received: 幽 May 14, 2019

Published: May 20, 2019

Citation: Sergei Pakriev. Tobacco Smoking in Patients of Therapeutic Hospital in Izhevsk, Russia. Biomed J Sci \& Tech Res 18(2)-2019. BJSTR. MS.ID.003114.

Keywords: Tobacco Smoking; Comorbidity; Risk Factors; Somatic Hospital
ABSTRACT

Background and 0bjectives: The paper's objective was to study the prevalence and risk factors of tobacco smoking in somatic patients of a therapeutic hospital

Methods: The subjects (323 adult patients) were selected using the method of continuous sampling. All subjects were asked to answer the questions from the Russian version of the Brief International Neuropsychiatric Questionnaire (MINI 5.0.0.)

Results: $77 \%$ (76.9\%) of men and $22.2 \%$ of women were smokers at the time of the study. The comorbidity of smoking was statistically significant for respiratory and digestive diseases, and alcohol addiction. The socio-demographic correlates of tobacco smoking were the male gender, age from 18 to 39 years, low level of education and unemployment.

Conclusion: Knowledge of the prevalence and risk factors of tobacco smoking can contribute to the targeted development and implementation of practical recommendations for a comprehensive treatment of somatic patients with comorbid tobacco addiction.

\section{Background and Objectives}

Tobacco smoking is an acute problem worldwide due to a high risk of various diseases and premature mortality [1]. According to the World Health Organization, tobacco smoking causes the death of every tenth adult. According to the WHO projections, by the year 2030 tobacco smoking will be a cause of death of every sixth person, provided no tobacco control measures are taken [2-4]. Nowadays, Russia is a leader in the number of smokers in the world [5] and is among the ten most smoking countries in the world, along with Poland, Turkey, Ukraine, China and Vietnam [5-7]. In Izhevsk, the problem of smoking was explored in 2005 by the staff of Izhevsk State Medical Academy and London School of Hygiene \& Tropical Medicine. The objective of this joint study was to identify the causes of premature death of working-age men in Izhevsk. In that study, relatives of 1,750 men who died from October 2003 to October 2005 at the age from 25 to 54 were interviewed. Additional unbiased information about the deceased was obtained in the Registry Office, the Pathoanatomical Bureau, and the Forensic Medical Bureau. According to the study findings, $40 \%$ of deaths were directly or indirectly related to alcohol consumption. Smoking and alcohol abuse caused $80 \%$ of men deaths. These two risk factors are related to the majority of premature deaths of working-age men in Izhevsk [8-10].

According to scientific literature, tobacco addiction, along with alcohol addiction and depression, is the most frequent comorbid psychiatric disorder in therapeutic and surgical units [11-14]. Comorbid tobacco addiction makes a somatic pathology worse, increases resistance to therapy, and increases the disability and mortality risks. The growing proportion of tobacco smoking patients in general hospitals requires a comprehensive study of the epidemiology of tobacco addiction combined with somatic diseases, and the development of comprehensive and more active therapy methods for this category of patients. At the moment, studies of tobacco smoking in therapeutic in-patients in Udmurtia are limited. The paper's objective was to study the risk factors, comorbidity and prevalence of tobacco addiction in hospitalized somatic patients of Izhevsk.

\section{Methods}

The research was carried out in Izhevsk, Russia, in therapeutic department 1 of City Hospital No. 5. The hospital had two therapeutic 
departments. Therapeutic department 1 ( 65 beds) was intended for prearranged and emergency hospitalization of the working-age and retired patients from the district the hospital is formally assigned to serve (with an adult population of 57,000 people, about $70 \%$ of whom are working age). Therapeutic department 2 was intended for the population with the official status of participants and disabled veterans of the Great Patriotic War's (Russian name for World War II) and equivalent categories of patients from Izhevsk. The average annual number of patients hospitalized to the first department was 1,220 people, more than a half of them aged 50 and older. The subjects were selected using the method of continuous sampling. The study group included every patient aged 18 to 59 . The average length of hospitalization per patient was 18.3 days. A total of 352 patients were selected for the study, but 29 of them (11 men and 18 women) were not included in the study for various reasons (refusal, severe somatic condition, etc.). Consequently, the study sample was 323 patients, including 147 (45.5\%) men and 176 (54.5\%) women. Ethnic background of the study population: 214 (66.3\%) Russians, 77 (23.8) Udmurts and 32 (9.9\%) other. All participants were divided into the following age groups: $18-39$ years-37\%, 4049 years-31\% and $50-59$ years-32\%. $71.5 \%$ of the study population were hospitalized due to exacerbation of a chronic somatic disease and $28.5 \%$ - due to an acute somatic disease.

All subjects were asked to answer the questions from the Russian version of the Brief International Neuropsychiatric Questionnaire (MINI 5.0.0.) [15]. Additionally, the survey used the diagnostic criteria of ICD-10 for organic mental disorders and the criteria for tobacco addiction. Information on somatic diagnoses, psychiatric consultations and prescribed psychotropic medications was obtained from medical records (medical history, patient records). Socio-demographic questions (gender, age, marital status, ethnic background, education and job) are part of MINI.

Table 1: Somatic diseases and tobacco smoking.

\begin{tabular}{|c|c|c|}
\hline Somatic Disease* & Total (N) & $\%$ \\
\hline Circulatory system diseases & 96 & 96 \\
\hline Respiratory system diseases & 85 & 85 \\
\hline Digestive system diseases & 66 & 66 \\
\hline Genitourinary system diseases & 23 & 23 \\
\hline Endocrine system diseases & 1 & 1 \\
\hline Musculoskeletal system diseases & 21 & 21 \\
\hline Neoplasms & 4 & 4 \\
\hline Pregnancy complications & 14 & 14 \\
\hline Injuries and poisonings & 3 & 3 \\
\hline Diseases of the skin and subcutaneous tissue & 5 & 5 \\
\hline Disorders of the hematopoietic system & 5 & 5 \\
\hline Acute diseases & 92 & 92 \\
\hline Chronic diseases & 231 & 231 \\
\hline Total & 323 & 323 \\
\hline
\end{tabular}

Note: In case of concomitant somatic diseases, only the principle diagnosis was considered.

Participation in the study was voluntary; the patients were informed of their right to refuse to participate. In case of consent, complete anonymity was guaranteed. Questioning and interviewing in each case were conducted during the first 72 hours of hospitalization. The diagnostic survey was conducted by three medical doctors who had been trained to use MINI at the Department of Psychiatry of Izhevsk State Medical Academy.

To analyze the data, STATISTICA 5.0 was used. The following tests were used: the t-test to compare average values (average age, etc.), the chi-square test to assess qualitative characteristics (gender, ethnic background, social status, etc.). To analyze comorbidity, Epi Info, Version 6 [16] was used. The comorbidity of tobacco addiction was determined as follows: the probability index of concomitant disease in the population with tobacco addiction was divided by the probability index of concomitant disease in the population without tobacco addiction.

\section{Results and Discussion}

According to the results of the study, $83.0 \%$ of men and $25 \%$ of women in the sample were regular tobacco smokers at some period of their lives (51.4\% of the whole sample). 126 people $(75.9 \%$ of all smokers) tried to quit smoking, and only $9.5 \%$ of them (12 people) abstained from tobacco for more than a year at the time of the interview. $77 \%(76.9 \%)$ of men and $22.2 \%$ of women were smokers at the time of the study. The number of tobacco addicted men (78.9\%) and women (17.1\%) (including those who quit smoking) is comparable with the number of heavy smokers that is $75.4 \%$ and $22.7 \%$ respectively. The respondents who smoked 15 or more cigarettes a day were included in the category of "heavy smokers" (Table 1) shows the structure of morbidity and tobacco smoking in the sample. The patients with acute forms of somatic diseases and with diseases of the respiratory and digestive systems smoked tobacco most often (Tables $1 \& 2$ ). 
Table 2: Most common somatic diseases and tobacco smoking

\begin{tabular}{|c|c|c|}
\hline Somatic Disease* & N (\%) of Male Smokers & N (\%) of Female Smokers \\
\hline Circulatory system diseases & $27(69.2)$ & $4(7.0)$ \\
\hline Respiratory system diseases & $42(80.8)$ & $13(39.4)$ \\
\hline Digestive system diseases & $34(87.2)$ & $10(37.0)$ \\
\hline
\end{tabular}

There were significantly more smokers among men, (Table 3), young and middle-aged people, those less educated or unemployed, and people engaged in manual labor. There was no significant correlation between smoking and the respondent's ethnicity. There was a tendency (insignificant) to a greater prevalence of smoking among single, widowed and divorced patients. There were other psychiatric disorders diagnosed in the sample: organic mental disorders-55.1\% (organic asthenia, organic personality disorder, cognitive disorder and dementia), depressive disorders- $20.7 \%$ alcohol addiction-24.8\%, social phobia-13.3\%, other anxiety disorders-6.5\% (ICD-10 codes: F40.01, F41.0, F41.1, F42.8). The comorbidity of tobacco addiction with other mental disorders was statistically significant for alcohol dependence (Table 4).There were other psychiatric disorders diagnosed in the sample: organic mental disorders-55.1\% (organic asthenia, organic personality disorder, cognitive disorder and dementia), depressive disorders-20.7\%

Table 3: Tobacco smoking and socio-demographic factors.

\begin{tabular}{|c|c|}
\hline Factors & Tobacco Smokers (\%) \\
\hline \multicolumn{2}{|l|}{ Gender } \\
\hline Male & 76.9 \\
\hline Female & 22.2 \\
\hline $\mathrm{P}$ (significance) & 0.000 \\
\hline \multicolumn{2}{|l|}{ Age } \\
\hline $18-39$ & 60.0 \\
\hline $40-49$ & 42.6 \\
\hline $50-59$ & 36.3 \\
\hline $\mathrm{P}$ & 0.001 \\
\hline \multicolumn{2}{|l|}{ Education } \\
\hline Primary and secondary & 54.6 \\
\hline Vocational and higher education & 41.1 \\
\hline $\mathrm{P}$ & 0.016 \\
\hline \multicolumn{2}{|l|}{ Social status } \\
\hline Physical labor & 59.7 \\
\hline Intellectual labor & 26.4 \\
\hline Disabled or retired & 35.2 \\
\hline Unemployed & 79.5 \\
\hline $\mathrm{P}$ & 0.000 \\
\hline \multicolumn{2}{|l|}{ Ethnic background } \\
\hline Russians & 47.7 \\
\hline Udmurts & 46.8 \\
\hline $\mathrm{P}$ & $*$ NS \\
\hline \multicolumn{2}{|l|}{ Marital status } \\
\hline Married & 43.7 \\
\hline Widowed or divorced & 48.8 \\
\hline
\end{tabular}

alcohol addiction-24.8\%, social phobia-13.3\%, other anxiety disorders-6.5\% (ICD-10 codes: F40.01, F41.0, F41.1, F42.8). The comorbidity of tobacco addiction with other mental disorders was statistically significant for alcohol dependence (Table 4). The age of 20 , and $88 \%$ of them under the age of 25 . Most smokers have been smoking for a long time: $96 \%$ have been smoking regularly for 5 years or more, and $75 \%$ have been smoking for more than 10 years. The most common tobacco products were cheap cigarettes with a high content of nicotine and tar (which significantly increases the death rate from lung cancer, according to Armadans-Gil et al. [18]. The comorbidity of smoking was statistically significant for respiratory and digestive diseases, and alcohol addiction. Tobacco smoking could be an indirect marker of depressive disorders: $40.4 \%$ of people with current depression smoked tobacco, and $24.7 \%$ of all smokers were diagnosed with depression. 


\begin{tabular}{|c|c|}
\hline Single & 59.5 \\
\hline $\mathrm{P}$ & NS (tendency) \\
\hline
\end{tabular}

Note: *NS-not significant.

Table 4: Comorbidity of tobacco smoking with other mental disorders.

\begin{tabular}{|c|c|c|c|}
\hline Comorbid Disorders & Smokers (\%) & Odds Ratio & 95\% CI \\
\hline Organic mental disorders & 46.1 & 1.08 & $0.68-1.72$ \\
\hline Social phobias & 39.5 & 0.77 & $0.38-1.54$ \\
\hline Other anxiety disorders & 23.8 & 0.36 & $0.11-1.07$ \\
\hline Alcohol addiction & 90.0 & 20.5 & $9.0-48.7$ \\
\hline Depression & 40.4 & 0.78 & $0.43-1.39$ \\
\hline
\end{tabular}

\section{Conclusion}

To sum up, the study findings indicate high prevalence of tobacco smoking in the sample, and, accordingly, an increased risk of death in this category of patients. The study findings present the problem not only at the level of the studied hospital, but also at the level of the general population of somatic patients in the whole city. This can contribute to the targeted development and implementation of practical recommendations for the comprehensive treatment of somatic patients with comorbid tobacco addiction.

\section{Conflict of Interest}

The authors have no conflicts of interest to report.

\section{References}

1. Levina TV, Krasnova Yu N (2013) Epidemiology of tobacco smoking Sicberian Medical Journal 121(6): 5-8.

2. (2004) Building blocks for tobacco control. WHO Tobacco Free Initiative pp. 285.

3. (2002) The Global Program on Evidence for Health Policy. WHO: World Health Report.

4. Maslennikova G Ya, Oganov RG (2008) Prevention and reduction of tobacco smoking in Russia: real opportunities for improving the demographic situation. Disease Prevention and Health Promotion $\mathrm{p}$. $3-10$.

5. (2009) Global survey of the adult population on tobacco consumption. Russian Federation: country report, Moscow.

6. (2006) Prevalence of smoking in the countries of the former USSR. Resource Center for Tobacco Control. Bulletin Kontakt.

7. R West, S Shiffman (2007) Fast facts: smoking cessation p.84.

ISSN: 2574-1241

DOI: 10.26717/BJSTR.2019.18.003114

Sergei Pakriev. Biomed J Sci \& Tech Res

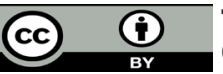

This work is licensed under Creative Commons Attribution 4.0 License

Submission Link: https://biomedres.us/submit-manuscript.php
8. Leon D, Saburova L, Tomkins S (2007) Hazardous alcohol drinking and premature mortality in Russia: The Izhevsk Family case-control study of men aged 25-54 years. The Lancet.

9. Leon D, Shkolnikov VM, Andreev EM (2006) Izhevsk family Study. General facts and conclusions.

10. Andreev EM, Zhdanov DA, Shkolnikov VM (2007) Mortality in Russia 15 years after the USSR collapse: facts and explanations. Electronic version of the newsletter Population and Society 311-312.

11. Agbayewa MO (1983) Recognition of organic mental disorders by physicians. Can Med Assoc J 128(8): 927-928.

12. Arolt V, Driessen M, Neubauer H, Schürmann A, Seibert W, et al. (1995) Psychiatric disorders in hospitalized internal medicine and surgical patients. Prevalence and need for treatment. Nervenarzt 66(9): 670-677.

13. Smaira SI, Kerr Corrêa F, Contel JO (2003) Psychiatric disorders and psychiatric consultation in a general hospital: a case- control study. Rev Bras Psiquiatr 25(1): 18-25.

14. Rothenhäusler HB (2006) Mental disorders in general hospital patients. Psychiatr Danub 18(3): 183-192.

15. Sheehan D, Lecrubier Y, Harnett Sheehan K, Amorim P, Janavs J, et al. (1998) The Mini International Neuropsychiatric Interview (M.I.N.I.): The Development and Validation of a Structured Diagnostic Psychiatric Interview. J Clin Psychiatry 59(20): 22-33.

16. Dean AG, Dean JA, Coulombier D (1994) Epi Info, Version 6: A word processing, database, and statistics program for epidemiology on microcomputers. Centers for Disease Control and Prevention, Atlanta, Georgia, USA.

17. (1998) Anonymous. Incidence of the initiation of cigarette smoking United States, 1965-1996. MMWR Morb Mortal Wkly Rep 47: 837-840.

18. Armadans Gil L, Vaque Rafart J, Rossello J, Olona M, Alseda M, et al. (1999) Cigarette smoking and male lung cancer risk with special regard to type of tobacco. Int J Epidemiol 28(4): 614-619.

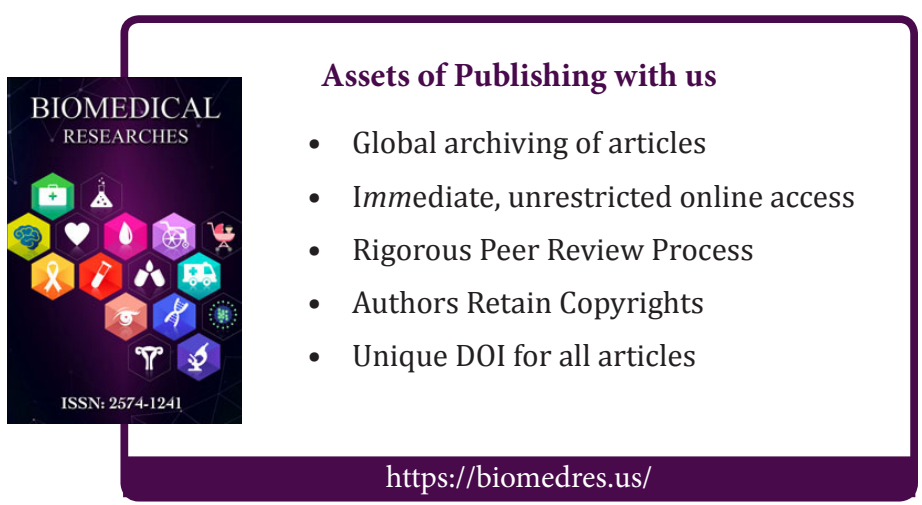

